\title{
A Causal Model of Lifestyle Modification Behaviors in Thai Adults with Hypertension
}

\author{
Patcharawadee TONGNUANG*, Piyanuch JITTANOON, \\ Umaporn BOONYASOPUN, Karnsunaphat BALTHIP and Diane Ruth LAUVER
}

Faculty of Nursing, Prince of Songkla University, Songkhla 90112, Thailand

('Corresponding author's e-mail: tpum82@hotmail.com)

Received: 29 May 2017, Revised: 5 December 2017, Accepted: 3 January 2018

\begin{abstract}
Lifestyle modification behaviors are a key strategy for controlling hypertension. Understanding the causal model of lifestyle modification behaviors would shape the behaviors which are necessary for controlling blood pressure levels among Thai adults with hypertension. The purpose of this study was to examine the proposed relationships between psychosocial variables, such as desire, attitude, perceived behavioral control (PBC), intention, trying, social support, illness identity, self-efficacy, and lifestyle modification behaviors (LMB). This study was a path analytic study using a self-administered questionnaire which was responded to by 240 selected Thai adults with hypertension at the out-patient clinic in 5 hospitals throughout Thailand. A set of questionnaires was used for collecting data and the internal consistency was between $0.75-0.95$. Data were analyzed by path analysis. The results found that PBC and social support had positive and direct influences on $\operatorname{LMB}(\beta=0.31, p<0.001 ; \beta=0.36, p<$ 0.001 , respectively). Desire and $\mathrm{PBC}$ had positive and direct influences on intention $(\beta=0.55, p<0.001$; $\beta=0.19, p<0.01$, respectively). Self-efficacy, intention, and $\mathrm{PBC}$ had positive and direct influences on trying $(\beta=0.46, p<0.001 ; \beta=0.19, p<0.01 ; \beta=0.15, p<0.05$, respectively). The revised model accounted for 47,30 , and $39 \%$ of the variance in intention, trying, and lifestyle modification behaviors, respectively. Knowledge about the factors influencing lifestyle modification behaviors in Thai adults with HTN will assist a nurse in developing interventions/programs to promote lifestyle modification behaviors in this population.
\end{abstract}

Keywords: Hypertension, lifestyle modification behaviors, Thailand, causal model

\section{Introduction}

Globally, increased blood pressure or hypertension (HTN) is estimated by WHO to be the leading risk factor for death [1]. Uncontrolled HTN increases the risk of diabetes neuropathy, stroke, and cardiovascular diseases. The working-age suffering from uncontrolled HTN would reduce the process of driving the economy in their country and on a personal level affects family income [2]. To prevent complications from uncontrolled HTN, adult aged group is of concern because the number of new patients with HTN was found in this group. In Thailand, almost 2.2 million Thai adults have been diagnosed with HTN [3]. Among the Thai adults with HTN who received prescribed medications, less than one-third had their HTN well-controlled [4]. Only $41.50 \%$ of adults with HTN could control their blood pressure level continuously (at least 2 times) in 2015 which had decreased from $42.70 \%$ of adults in 2014 [5]. Consequently, the mortality rate of HTN increased from 2013 to 2015 which was due to uncontrolled hypertension [6].

Because of the difficulty to change several behaviors to control blood pressure, the failure of blood pressure control still is a significant problem in adults with HTN. From previous studies, many reasons 
were found to impede the control of blood pressure among adults with HTN [7-9] and these included lack of knowledge, less awareness, or a low degree of intention. Additionally, previous studies [10-12] indicated that adults with HTN who lacked a goal setting and had low confidence of his/her ability to fulfill the essential behaviors to achieve a desired goal were more likely to have a low intention for the continual change of lifestyle behaviors. Moreover, a nurse was a key person who had knowledge, skills, and competency to take care adults with HTN. Several experimental studies in nursing [13-16] were conducted in several past years to promote lifestyle modification behaviors; however, the failure of controlling blood pressure levels still increases in this population. Thus, overcoming the barriers and appropriate nursing cares would help adults with HTN to improve their blood pressure levels.

To prevent and control blood pressure, adults with HTN should perform lifestyle modification behaviors (LMB). The LMB are a key strategy of non-pharmacologic treatment to control hypertension $[13,17]$. The JNC-8 guidelines emphasized that lifestyle treatment has the potential to improve blood pressure control and even reduce medication needs $[13,18]$. Both guidelines stated that LMB consists of weight reduction, adopting the Dietary Approach to Stop Hypertension (DASH) eating plan, sodium reduction, physical activity, and limiting alcohol consumption, which are similar with the recommendations from the Thai Hypertension Society [19]. Following these guideline recommendations of LMB including dietary consumption, physical activity, avoiding risks, stress management, and seeking follow up still are important in adults with HTN. To gain success in changing LMB among adults with HTN in the long term, using an appropriate model of LMB should be of concern in nursing.

Four existing models about LMB among adults with hypertension were found in Korea, Taiwan, USA, and Thailand; however, there were differences among these existing models. A study by Yang et al. [20] proposed the model of blood pressure control among hypertensive adults in Korea but all of the factors were non-modifiable. Chen et al. [11] tested a model based on the common-sense model of illness representation in Taiwan. Most of the factors of these 2 previous models were non-modifiable factors $[11,20]$. Another previous model in the USA examined the psychosocial factors based on MGB [21,22]. In Thailand, Pinprapapan et al. [23] examined the association between cognitive and social factors and adherence to therapeutic regimens in women with HTN. This study was undertaken in women and conducted in one province. The existing knowledge from the previous models contributed to our understanding of HTN in a variety of populations and explanatory variables. Few studies in Thailand presented a proposed model of LMB. Thus, having an understanding about the causal model of LMB would shape the behaviors which were necessary for controlling blood pressure levels among Thai adults with HTN.

In this study, the hypothesized model of LMB in Thai adults with hypertension was developed based on theory and empirical studies which had powerful predictive ability of each independent variable toward dependent variable both in Thailand and other countries (Figure 1). The Model of Goal-Directed Behavior (MGB) was used to guide this study [24]. Four variables of MGB including attitude, perceived behavioral control, desire, and intention were selected to propose the hypothesized model because some propositions of these variables were supported in previous studies [21,22]. Attitude refers to the functions of a decision maker's beliefs about the action and his/her evaluations of doing it [22]. Perceived behavioral control (PBC) is formed by individual perceptions of resources or barriers to act the behavior and perceived power of each control factor to facilitate/impede the behavior [25]. Desire is implied to the intensity or level with which a goal is sought and serves to integrate a series of emotional, cognitive, selfperception, and social appraisal of a person prior to intention formation [22]. Consequently, desires are thought to be essential mediators of attitudes and the other antecedents on intentions to act. Intention is assumed to capture the motivational factors that influence a behavior, and it is indicated by how hard people are willing to try, how much of an effort people are planning to exert, in order to perform the behavior [25].

In addition, 4 empirical variables including social support, trying, self-efficacy, and illness identity were added in the hypothesized model. Social support was indicated as one of important determinants of success in motivation to change and maintain behaviors for hypertension management, because of its reported large influence on LMB in Thai adults with hypertension [26-28]. Trying plays a key process intervening between intentions and behavior. To fulfill an individual's goal, he/she must see his/her own 
action as a purposive attempt where foresight and effort are needed [22]. Self-efficacy is defined as an individual's confidence in his/her ability to perform a specific behavior [29]. Self-efficacy was indicated as an important factor of LMB because of significant results from several previous studies [7,23,30]. Moreover, illness identity refers to the label or name given to the condition and the symptoms that appear to go with an illness [31]. When a symptom is presented, patients usually look for causes of the illness and change their actions to cope with the illness. Previous studies found the negative and indirect influences from illness identity to healthy diet, unhealthy diet, exercise regimen, and appointment keeping among patients with HTN [18,32].

In summary, previous studies supported the proposition and provided inconclusive evidence regarding the relationship between desire, attitude, PBC, intention, trying, social support, illness identity, self-efficacy, and LMB. Accordingly, a total of 9 variables were assessed. A hypothesized model of LMB in Thai adults with HTN was proposed, as shown in Figure 1. Attitude and PBC were expected to have positive and direct influences on LMB via intention and trying. Desire would positively and indirectly influence on LMB via intention. Also, self-efficacy, social support, and illness identity would affect LMB directly. Thus, the purpose of this study was to examine a hypothesized model of LMB in Thai adults with hypertension.

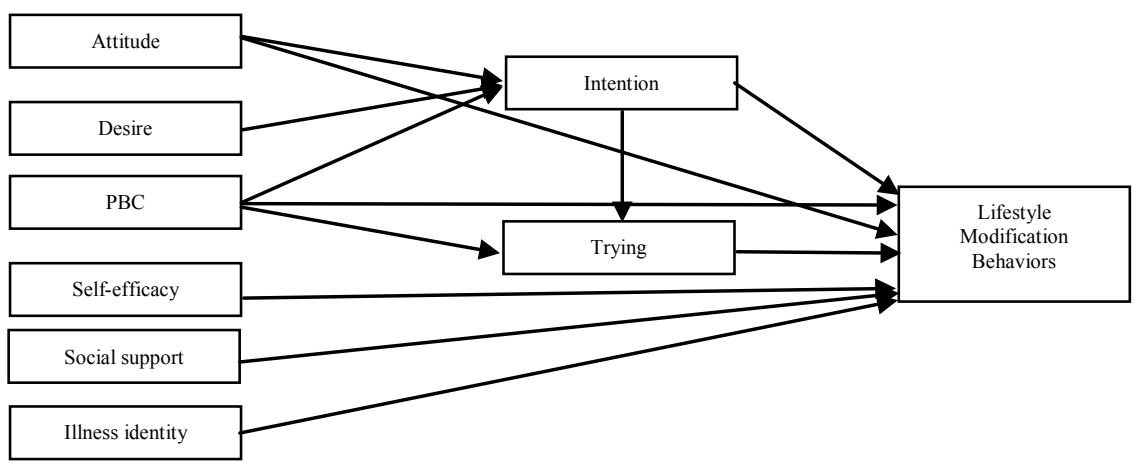

Figure 1 A hypothesized model of lifestyle modification behaviors in Thai adults with hypertension.

\section{Materials and methods}

\section{Sample and sampling}

A path analytic study was designed. The target population was Thai adults who had been diagnosed with hypertension by physicians. We used a 4-stage random sampling procedure: (a) we determined the need for samples who were chosen from 5 different regions of Thailand; (b) samples were chosen from out-patient clinics at hospitals serving the 5 regions; (c) based on population figures, the number of samples was proportionate with the number of out-patient adults with hypertension who followed up at the hypertension clinic in each selected hospital (Table 1); and (d) respondents who met the inclusion criteria for the study and provided informed consent. This method yielded a probability sample of 240 Thai adults with hypertension. Nunnally and Bernstein [33] recommended at least 30 samples per independent variable. The criteria for a sample's inclusion were as follows: (a) aged between 35 and 59 years old; (b) have been diagnosed with essential hypertension; (c) have taken antihypertensive drugs for at least 6 months; and (d) understood the study and agreed to participate. Samples with a medical history of serious mental and physical illness were excluded. 
http://wjst.wu.ac.th

Table 1 Number of participants proportionate with the number of out-patient adults who followed up at hypertension clinics in selected hospitals.

\begin{tabular}{lccc}
\hline \multicolumn{1}{c}{ Hospital name } & $\begin{array}{c}\text { Number of adult out-patients in } \\
\text { selected hospitals }\end{array}$ & $\begin{array}{c}\text { Proportion } \\
\text { allocation }\end{array}$ & $\begin{array}{c}\text { Number of } \\
\text { samples }\end{array}$ \\
\hline 1. Somdetphraphutthalertla & 2,776 & $(2,776 \times 240) / 14,723$ & 45 \\
2. Mahasarakham & 1,469 & $(1,469 \times 240) / 14,723$ & 24 \\
3. Naradhiwasrajanagarindha & 3,743 & $(3,743 \times 240) / 14,723$ & 61 \\
4. Nan & 4,289 & $(4,289 \times 240) / 14,723$ & 70 \\
5. Trat & 2,446 & $(2,446 \times 240) / 14,723$ & 40 \\
Total & $\mathbf{1 4 , 7 2 3}$ & & $\mathbf{2 4 0}$ \\
\hline
\end{tabular}

\section{Instruments}

A set of questionnaires was used to collect the data. Sociodemographic data consisted of age, gender, occupation, education, marital status, religion, monthly income, family members, source of knowledge about hypertension control, and history of hypertension such as the year of having been diagnosed with hypertension, previous blood pressure levels over the last few visits, comorbidities, taking anti-hypertensive drugs and other drugs, future appointments recommended in weeks were obtained. To measure some explanatory variables associated with the MGB including attitude, perceived behavioral control, desire, intention, and trying, the researchers used questionnaires that were previously used by Taylor et al. [22], however, some words in our questionnaire were changed to make them appropriate with Thai cultural context. Other questionnaires such as social support, self-efficacy, and illness identity were modified from previous studies also. A back translation from English to a Thai version was done in some questionnaires. The questionnaires are as follows;

Attitude for lifestyle modification behaviors was measured by a 3-item with a 5-point scale questionnaire. Samples were assessed by 'considering all the effort and things, I would have to do to reduce (maintain) my blood pressure during the next 4 weeks' (for example, dieting, exercising, avoiding risks, managing my stress, and seeking follow up) and 'my overall attitude toward doing these things makes me feel... The 3 bipolar items were responded with very unpleasant/very pleasant, very bad/very good, and very unhappy/very happy. A total score near 10 indicates a high attitude for lifestyle modification behaviors in hypertension. Cronbach's $\alpha$ coefficient of internal consistency reliability for this study was 0.78 .

Perceived behavioral control was determined from 3 question items with a 5-point scale. The sample responded to 'Please indicate how much control you have regarding your blood pressure during the next 4 weeks'. A total score near 15 indicates high perceived behavioral control of lifestyle modification behaviors in hypertension. Cronbach's $\alpha$ coefficient was 0.85 .

Desire for lifestyle modification behaviors was measured from 2 items which followed a 5-point scale. The first item asks about 'I want to reduce (maintain) my blood pressure during the next 4 weeks.' The second asks patients to indicate their degree of desire in response to the following statement that is 'my desire to reduce (maintain) my blood pressure during the next 4 weeks can best be expressed as ...' A total score near 10 indicates a high desire for lifestyle modification behaviors in hypertension. The internal consistency reliability was tested and the Cronbach's alpha coefficient was 0.80 .

Intention to adopt lifestyle modification behaviors asked about 'I intend to reduce (maintain) my blood pressure during the next 4 weeks' and 'I plan to reduce (maintain) my blood pressure during the next 4 weeks' and are measured on a 5-point scale in 2 items. A total score near 10 indicates a high intention to adopt lifestyle modification behaviors in hypertension. Cronbach's $\alpha$ coefficient of internal consistency reliability for this study was 0.75 . 
http://wjst.wu.ac.th

Trying to adopt lifestyle modification behaviors was measured with four 5-point items. Samples were asked about how hard did you try (to reduce/maintain your blood pressure) during the past 4 weeks in each of the following senses: (1) devoting time for planning with respect to however you go about trying to reduce blood pressure, (2) expending a lot of mental/physical energy to reduce (maintain) your blood pressure, (3) maintaining your will power to reduce (maintain) your blood pressure, and (4) sustaining your self-discipline to reduce (maintain) your blood pressure. A total score near 20 indicates high consistency trying to adopt lifestyle modification behaviors. Cronbach's $\alpha$ coefficient was 0.95.

Social support for hypertension was determined using the Hypertensive Social Support Scale developed by Pinprapapan et al. [23]. The samples responded to received help or assistance from a person with whom they were in a personal relationship with during the past month in the 4 aspects of emotional support, instrumental support, informational support, and appraisal support. The scale consists of 23 items scoring from not true (1) to strongly true (4). The higher scores mean high social support for hypertension. The internal consistency reliability was accepted at Cronbach's $\alpha$ coefficient of 0.93 .

Self-efficacy was measured by the Hypertensive Perceived Self-Efficacy Questionnaire (HPSEQ) which was modified from the Self-Efficacy for Managing Chronic Disease 6-Item Scale (SES6C) [34]. A back translation from English to a Thai version was also done. Content validity of the HPSEQ Thai version was evaluated and adjusted for appropriate vocabulary by 3 experts. One item was deleted because it did not fit with this population. Thus, the HPSEQ has 5 items with a 5-point scale ranging from "not at all confident" ( 1 score) to "totally confident" ( 5 score). A high score reveals high confidence in a patient's ability for lifestyle modification behaviors in hypertension. Cronbach's $\alpha$ coefficient was 0.91 .

Illness identity was assessed from the Illness Identity Scale (Thai Version) [35]. We changed and deleted some symptom items which did not present clearly or frequently in adults with hypertension. The scale in this study was 5 items. Respondents were asked "Do you think your high blood pressure causes you to experience the following symptoms?" The symptom item with "yes" response was scored 1. A total score near 5 indicates a high perception about the symptoms of hypertension. The internal consistency reliability was 0.77 .

Lifestyle modification behaviors asked about the frequency of an action for changing a behavior to control blood pressure levels in the past month. The researchers modified the Lifestyle Modification Behaviors Questionnaire (LMBQ) from Limcharoen [36] by adding items recommended for controlling blood pressure from the $8^{\text {th }}$ Joint National Committee Hypertension Guidelines [18] and the Thai Hypertension Society [10]. The LMBQ has 30 items and is measured on a 4-point scale with responses from 'never' ( 1 score) to 'always' (4 scores). This questionnaire was divided into the following 5 subscales of dietary consumption, physical activity, avoiding risks, stress management, and seeking follow up. A high score reveals a high level of lifestyle modification behaviors for hypertension. Cronbach's $\alpha$ coefficient was 0.91 .

\section{Data collection}

This study was approved by the Research Ethics Committee of Faculty of Nursing, Prince of Songkla University and the institutional review boards of the hospitals who took part in this study (MOE 0521.1.05/0312). No ethical concerns other than the usual protection for human subjects in research were identified. Before collecting the data, the researchers explained to the samples about the study and obtained informed consent. The researchers and one research assistant used a set of self-report questionnaires and personal health-record information to collect data. The samples completed all questionnaires which took approximately 60 to $90 \mathrm{~min}$. The research team read the questionnaires for those who were illiterate or were fatigued. Upon completion, the research team checked each completed questionnaire, obtained additional information, and thanked the participants for their participation in this study. 


\section{Data analysis}

Descriptive statistics and assumptions underlying multivariate analysis including normality, linearity, homoscedasticity, and multicollinearity were determined using a computer program. Statistical significance was set at $p<.05$. Path analysis was used to examine the relationship between the explanatory variables and lifestyle modification behaviors and to test the hypothesized model. For evaluating the goodness of fit of the model, the researchers used the following goodness of fit indices: a relative chi-square $(\chi 2 / \mathrm{df})>3$ [37,38], goodness-of-fit index (GFI) $\geq 0.90$ [39], comparative fit index $(\mathrm{CFI}) \geq 0.90$ [33], root mean square error of approximation (RMSEA) $<0.60$ [39], and standardized root mean square residual $(\mathrm{SRMR}) \leq 0.80$ [38]. These fit indices are robust to sample size and model misspecifications.

\section{Results and discussion}

Results

The characteristics of the sample in this study was presented in Table 2.

Table 2 Characteristics of study samples.

\begin{tabular}{lc}
\hline Characteristics & $\mathbf{\%}$ \\
\hline Female & 62.9 \\
Married & 80.4 \\
Lived with family (1 - 4 members) & 76.7 \\
Diagnosed with hypertension $<5$ years & 54.2 \\
Had comorbidities & 51.2 \\
Systolic blood pressure levels $\geq 140 \mathrm{mmHg}$ & 34.1 \\
Diastolic blood pressure $\geq 90 \mathrm{mmHg}$ & 20.0 \\
Received HTN knowledge from health care teams & 97.1 \\
\hline
\end{tabular}

The results of path analyses presented the relationships between selected variables and LMB and the model fit. For the hypothesized model, the chi-square was 76.06 and degree of freedom $(d f)$ was 9 , with a significant chi-squared test result $(p=0.00)$. The goodness-of-fit indices were RMSEA $=0.18, \mathrm{GFI}=$ $0.94, \mathrm{CFI}=0.90$, and SRMR $=0.08$. Given that some of the goodness of fit values did not support the hypothesized model, the researchers conducted exploratory analyses on an alternative model. To improve the goodness-of-fit of the model, the researchers revised the proposed model based on findings from prior model testing and theoretical reasons. The largest modification index (60.88) was from self-efficacy to trying. Because this parameter is meaningful and theoretically sound, a direct path from self-efficacy to trying was added. The revised model obtained is presented in Figure 2. The insignificance of the chisquare test result $(p=0.06)$ and the goodness-of-fit indices (RMSEA $=0.06, \mathrm{GFI}=0.99, \mathrm{CFI}=0.99$, and SRMR $=0.02)$ indicated that the revised model exhibited a fit to the data. The standard path coefficients and proportions of variance of the endogenous variables explained $\left(\mathrm{R}^{2}\right)$ are shown in the path diagram (see Figure 2). The revised model accounted for 47,30 , and $39 \%$ of the variance in intention, trying, and LMB, respectively. The total effects, both direct and indirect, of the selected explanatory variables of LMB are presented in Table 3. 


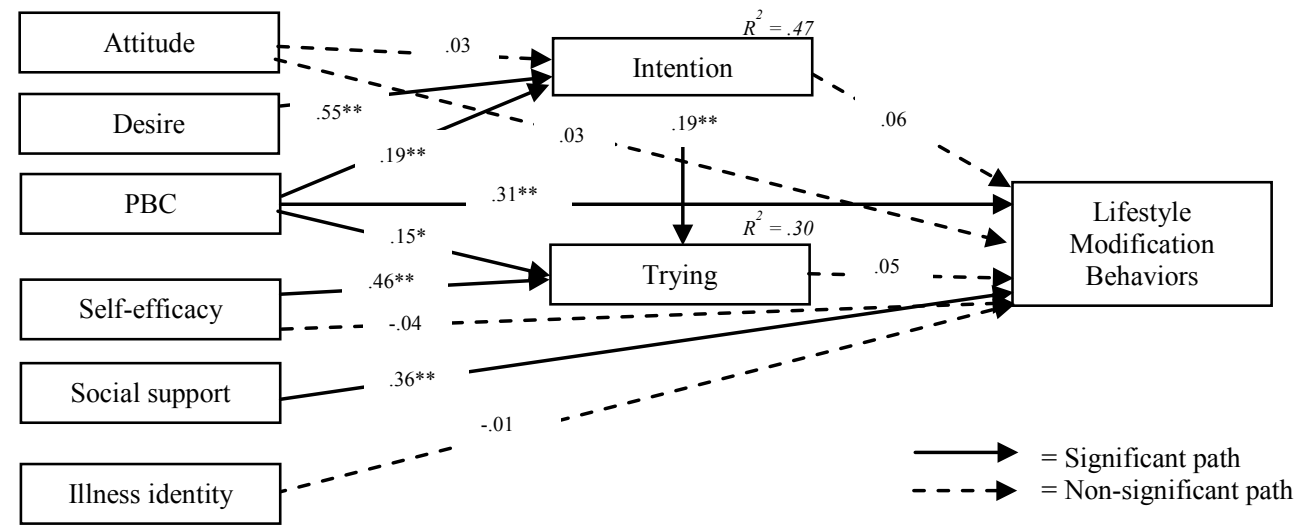

Figure 2 A revised model of lifestyle modification behaviors in Thai adults with hypertension.

Table 3 Total, indirect, and direct effects in the revised model.

\begin{tabular}{llllllllll}
\hline \multirow{2}{*}{ Variables } & \multicolumn{3}{c}{$\mathbf{L M B}^{\mathrm{a}}$} & \multicolumn{3}{c}{ Intention } & \multicolumn{3}{c}{ Trying } \\
\cline { 2 - 10 } & $\mathbf{I E}^{\mathbf{c}}$ & $\mathbf{D E}^{\mathbf{d}}$ & $\mathbf{T E}^{\mathbf{e}}$ & $\mathbf{I E}$ & $\mathbf{D E}$ & $\mathbf{T E}$ & $\mathbf{I E}$ & $\mathbf{D E}$ & $\mathbf{T E}$ \\
\hline Intention & .01 & .06 & .07 & - & - & - & - & $.19^{* *}$ & $.19^{* *}$ \\
Trying & - & .05 & .05 & - & - & - & - & - & - \\
Attitude & .00 & .03 & .03 & - & .03 & .03 & .01 & - & .01 \\
PBC $^{\mathrm{b}}$ & .02 & $.31^{* *}$ & $.33^{* * *}$ & - & $.19^{* *}$ & $.19^{* *}$ & $.04^{*}$ & $.15^{*}$ & $.18^{*}$ \\
Self-efficacy & .02 & -.04 & -.01 & - & - & - & - & $.46^{* * *}$ & $.46^{* * *}$ \\
Social support & - & $.36^{* * *}$ & $.36^{* * *}$ & - & - & - & - & - & - \\
Illness identity & - & -.01 & -.01 & - & - & - & - & - & - \\
Desire & .04 & - & .04 & - & $.55^{* * *}$ & $.55^{* * *}$ & $.10^{*}$ & - & $.10^{*}$ \\
\hline
\end{tabular}

Note: ${ }^{\text {a }}$ Lifestyle modification behaviors, ${ }^{\mathrm{b}}$ Perceived behavioral control, ${ }^{\mathrm{c}}$ Indirect Effects, ${ }^{\mathrm{d}}$ Direct Effects, ${ }^{\mathrm{e}}$ Total effects, ${ }^{*} p<.05, * * p<.01, * * * p<.001$.

\section{Discussion}

The present study is the first to adopt the MGB to investigate the relationship between selected explanatory variables, intention, trying, and LMB in Thai adults with HTN. Previous studies only assumed a relationship between explanatory variables and trying for self-regulation in HTN [21,22]. There is a lack of research investigating the interrelationship among these variables. Additionally, knowledge about Asian adults with HTN in this context is even limited. The revised model accounted for 47,30 , and $39 \%$ of the variance in intention, trying, and LMB, respectively. Using path analysis to analyze all of the variables simultaneously, the findings present an overall path model linking the selected explanatory variables, intention, trying, and LMB with a directional pathway. This can help to enhance the understanding of the interrelationships between these variables. 
PBC and social support were identified as affecting LMB. Three explanatory variables (selfefficacy, PBC, and intention) affected trying for LMB. Desire and PBC significantly influenced trying for $\mathrm{LMB}$, and they were mediated by intention. The positive relationship between selected explanatory variables, intention, trying, and LMB in this study supports MGB. Indeed, previous studies have found that selected explanatory variables were associated with trying for self-regulation in HTN [21,22]. This model also helps to expand our knowledge of psycho-social factors, such as social support and PBC, which would influence the adoption of LMB in Thai adults with HTN.

The finding shows that desire has a direct impact on intention and PBC influences LMB directly. These 2 propositions are consistent with the MGB proposed by Perugini and Bagozzi [24]. Desire provides the motivational impetus for intentions, that is, persons accept their desire to act, and this will motivate them to form an intention. High degrees of desire are more likely to increase intention for LMB. The findings are in line with previous studies in that adults with HTN who have a greater desire tend to have better intention for LMB [21,22]. Furthermore, PBC can be used directly to predict behavioral achievement [40]. The finding supports this relationship and is in line with previous studies [11,41]. Strongly perceived opportunities and resources and having high levels of perceived ability to control can help adults with HTN perform the behaviors and succeed in controlling blood pressure levels.

Based on empirical evidence, the researchers proposed that social support would be related to LMB. The finding confirms the association between social support and LMB and corresponds with several previous studies $[23,28,42]$, especially in Thailand. Possibly, in Asian cultures including Thai culture, Thai families are brought up to have close family ties and to respect adults or the elderly, thus when a family member suffers from an illness he or she will seek help and care from their family first [27]. Consistently, most of the participants lived with family which means that having relationships with relatives and friends can affect an individual's social relationships directly and enhance received support [43]. Social support can induce or facilitate a person to get support for acting or modifying a behavior following the advice or supporter [28]. Similarly, most participants received information and suggestions about HTN from healthcare personnel. Thus, social support appeared to be an important determinant of success in motivation for changing and maintaining a behavior such as the recommended behaviors for blood pressure control.

Additionally, the path from self-efficacy to trying was added during model modification. The final model found that self-efficacy had a positive and direct influence on trying for LMB which was the second highest magnitude path in the revised model. The finding was surprising because none of the previous studies reported this relationship. It might be due to the participants having had a lot of experience with HTN which would lead them to try to adopt LMB. People with a high level of selfefficacy tend to be more likely to try or maintain a behavior [44].

Regarding attitude, the findings present that attitude did not have a positive influence on intention, trying, and LMB both directly and indirectly. Possibly, the measurement of attitudes might have been affected by a social desirability bias that seems to affect people's evaluation of reactions toward LMB. This finding is similar to the previous study [21] which indicated that higher attitudes did not create higher intentions in both African American men and women with HTN. In addition, the researchers had proposed illness identity could explain LMB. However, illness identity did not have an influence on LMB. The possible reason may be due to asymptomatic HTN. It is true to say that high blood pressure or HTN is largely a silent and invisible killer that rarely causes symptoms [2,45]. In this case, because HTN is symptomless, patients are more likely to avoid changing their lifestyle behaviors to control blood pressure levels. This is congruent with previous studies in Thailand $[35,46]$, in which these studies found that most Thais visited a hospital when their symptoms were advanced. They gave reasons that in the early stage of HTN often no symptoms showed so that the sufferer could not detect high blood pressure by him/herself.

In relation to intention and trying, the researchers proposed that these 2 variables would have an influence on LMB. However, the findings did not support this relationship. It is possible that intentions were affected by situations in the workplace which might intervene and disrupt the relationship between attitude and LMB. Most of the participants were in the workforce age group and most of them had a job $(87.50 \%)$. Difficulties of execution in behavior performance may limit volitional control [40]. In 
http://wjst.wu.ac.th

addition, LMB consisted of 5 sub-behaviors (dietary consumption, physical activity, avoiding risks, stress management, and seeking follow up). Changing multiple behaviors needs a number of attempts to be successful. It might be that when a person tried to perform these behaviors and experienced failure, they tended to quit the behaviors. These results are inconsistent with the theory and previous findings $[21,22,41]$ in that intention and trying would have an influence on behaviors.

This study likewise provides implications for clinical practice. A nurse could incorporate the findings to identify adults who are required to change lifestyle behaviors to control hypertension and to develop an assessment tool to screen those who are at risk for lower levels of LMB, such as an adult with lower social support, an adult with lower PBC, so that an individualized plan of care could be delivered to develop LMB for adults with HTN. Furthermore, this model could help to deepen our understanding of the effect of the explanatory variables on LMB and the mediating role of 2 variables (intention and trying), so that tailor-made interventions can be designed to target the modifiable variables and to modify the mediating variable in order to change the outcome. The nurse could collaborate with the healthcare team to design an intervention to promote adults with HTN in the change of LMB. Besides, an intervention to improve the LMB of adults with HTN, such as increasing social support and promoting PBC, could be effective in changing the outcome.

The strength of this study was the use of a theoretical model to guide the research. This study evaluated the predictive utility of the model among Thai adults with HTN, which was guided by the MGB. The findings provided an extension of the model for explaining about LMB in another culture. However, this study has some limitations. First, because all the variables from MGB were not included, the researchers could not claim to have tested the whole model as others have done [20,21]. A second limitation is that our study was a cross-sectional design which measured a single point in time, and it is possible that an individual's assessment of his or her perceptions changes over time due to individual conditions. Future research could lead to the development of programs that help adults with HTN to change their lifestyle behaviors to control their blood pressure levels. Additional exploration may be directed towards examining strategies that may increase intention and trying by promoting social support, PBC, self-efficacy to modify lifestyle behaviors. To confirm the whole MGB in Thai adults with HTN, future research is needed to test all the variables.

\section{Conclusions}

Overall, the results of this study revealed an understanding of LMB and their associated factors among Thai adults with HTN. Knowledge of the interrelationships of the explanatory variables gives us a better understanding of this phenomenon. Key factors, social support and PBC influenced the LMB in this study. An increased intention, PBC, and self-efficacy increased trying for LMB. Also, a strong desire and PBC enhanced intention for LMB. It is imperative that a nurse addresses support, strategies, and solutions that may facilitate a higher level of LMB among Thai adults with HTN. Consequently, this study will contribute to clinical application and result in a foundation for further integrated interventions/programs for improving or promoting the LMB among Thai adults with HTN.

\section{Acknowledgements}

This work is supported by Office of the Higher Education Commission, Ministry of Education, and Princess of Naradhiwas University, Thailand.

\section{References}

[1] World Health Organization. A Global Brief on Hypertension: Silent Killer, Global Public Health Crisis. World Health Organization, Switzerland, 2013.

[2] World Health Organization. Available at: http://apps.who.int/iris/bitstream/10665/170250/1/ 9789240694439 _eng.pdf, accessed December 2016. 
http://wjst.wu.ac.th

[3] Thai Ministry of Public Health. Available at: https://hdcservice.moph.go.th/hdc/reports/ report.php? source=formated/format_1.php\&cat_id=6a1fdf $282 \mathrm{fd} 28180 \mathrm{eed} 7 \mathrm{~d} 1 \mathrm{cfe} 0155 \mathrm{e} 11 \& \mathrm{id}=29 \mathrm{eec} 762 \mathrm{c} 9591 \mathrm{~d}$ 1 f8092da14c7462361, accessed May 2017.

[4] $\mathrm{T}$ Pangjunant and $\mathrm{N}$ Panthuvaj. Available at: http://www.thaincd.com/news/hot-newsview.php?id=9129, accessed August 2015.

[5] Bureau of Non-Communicable Disease Thailand. The Annual Report 2015. The War Veterans Organization of Thailand under Royal Patronage of His Majesty the King Press, Bangkok, 2016.

[6] A Pakdeepinit, S Kaewklin and S Khongchin. Available at: http://www.thaincd.com/document/file/ info/non-communicable-disease2559.pdf, accessed December 2016.

[7] BD Rigsby. Hypertension improvement through healthy lifestyle modifications. J. Assoc. Black Nurs. Facul. High. Educ. 2011; 22, 41-3.

[8] M Rocha-Goldberg, L Corsino, B Batch, CI Voils, CT Thorpe, HB Bosworth and LP Svetkey. Hypertension improvement project (HIP) Latino: Results of a pilot study of lifestyle intervention for lowering blood pressure in Latino adults. Ethn. Health 2010; 15, 269-82.

[9] Y Ruixing, L Hui, W Jinzhen, L Weixiong, Y Dezhai, P Shangling and L Xiuyan. Association of diet and lifestyle with blood pressure in the Guangxi Hei Yi Zhuang and Han populations. Public Health Nutr. 2009; 12, 553-61.

[10] PA James, S Oparil, BL Carter, WC Cushman, C Dennison-Himmelfarbet, J Handler, DT Lackland, ML LeFevre, TD MacKenzie, MO Ogedegbe, SCJ Smith, LP Svetkey, SJ Taler, RR Townsend, JTJ Wright, AS Narva and E Ortiz. 2014 evidence-based guideline for the management of high blood pressure in adults. J Am. Med. Assoc. 2014, 311, 507-20.

[11] Thai Hypertension Society. Thai Guidelines on the Treatment of Hypertension Updates 2012. Huanam Printing, Bangkok, 2012.

[12] CD Ford, MJ Kim and BL Dancy. Perceptions of hypertension and contributing personal and environmental factors among rural Southern African American women. Ethn. Dis. 2009; 19, 40713.

[13] LL Lee, MC Watson, CA Mulvaney, CC Tsai and SF Lo. The effect of walking intervention on blood pressure control: A systematic review. Int. J. Nurs. Stud. 2010; 47, 1545-61.

[14] A Chanasuk. 2009, Effect of Dietary Behavioral Modification Program on Blood Pressure in Persons with Hypertension. Master's Thesis, Pathumthani, University, Bangkok, Thailand.

[15] S Champoo. 2008, Effectiveness of Self-management Program on Health Behavior and Blood Pressure among Hypertensive Patients. Master's Thesis, Burapha University, Chonburi, Thailand.

[16] CW Chiu and F Wongb. Effects of 8 weeks sustained follow-up after a nurse consultation on hypertension: A randomised trial. Int. J. Nurs. Stud. 2010; 47, 1374-82.

[17] JL Middleton. A proposed new model of hypertensive treatment behavior in African Americans. $J$. Natl. Med. Assoc. 2009; 101, 12-7.

[18] S Chen, J Tsai and K Chou. Illness representations and adherence to therapeutic regimens among patients with hypertension: A structural modeling approach. Int. J. Nurs. Stud. 2011; 48, 235-45.

[19] M Scisney-Matlock, HB Bosworth, JN Giger, OL Strickland, RV Harrison, D Coverson, NR Shah, CR Dennison, JM Dunbar-Jacob, L Jones, G Ogedegbe, ML Batts-Turner and KA Jamerson. Strategies for implementing and sustaining therapeutic lifestyle changes as part of hypertension management in African Americans. Postgrad. Med. J. 2009; 121, 147-59.

[20] SJ Yang, D Jung and AE Choi. Prediction model of blood pressure control in community-dwelling hypertensive adults in Korea. Nurs. Health Sci. 2010; 12, 105-12.

[21] M Baghianimoghadam, S Aivazi, SS Mzloomy and B Baghianimoghadam. Factors in relation with self-regulation of hypertension based on the Model of Goal Directed behavior in Yazd city. J. Med. Life 2011; 4, 30-5.

[22] SD Taylor, RP Bagozzi and CA Gaither. Decision making and effort in the self-regulation of hypertension: Testing two competing theories. Brit. J. Health Psychol. 2005; 10, 550-30.

[23] E Pinprapapan, S Panuthai, T Vannarit and W Srisuphan. Causal model of adherence to therapeutic regimens among Thais with hypertension. Pac. Rim Int. J. Nurs. Res. Thai. 2013; 17, 268-81. 
http://wjst.wu.ac.th

[24] M Perugini and RP Bagozzi. The role of desires and anticipated emotions in goal-directed behaviors: Broadening and deepening the theory of planned behavior. Brit. J. Soc. Psychol. 2001; 40, 79-98.

[25] I Ajzen. The theory of planned behavior. Organ. Behav. Hum. Decis. Process. 1991; 50, 179-211.

[26] AD Heymann, R Gross, H Tabenkin, B Porter and A Porath. Factors associated with hypertensive patients' compliance with recommended lifestyle behaviors. Isr. Med. Assoc. J. 2011; 13, 553-7.

[27] P Purateeranrath. Health beliefs and social support with self-care of essential hypertension patients at Surin hospital, Surin Province. Med. J. Srisaket Surin Buriram Hospitals 2011; 26, 449-62.

[28] S Sukprungprom. 2008, Factors Related to Health Promoting Behavior of Hypertension Patients in Amphawa District, Samut Songkhram Province. Master's Thesis, Mahidol University, Bangkok, Thailand.

[29] E Pinprapapan, S Panuthai, T Vannarit and W Srisuphan. Causal model of adherence to therapeutic regimens among Thais with hypertension. Pac. Rim Int. J. Nurs. Res. Thai. 2013; 17, 268-81.

[30] BC Wingo, RA Desmond, P Brantley, L Appel, L Svetkey, VJ Stevens and JD Ard. Self-efficacy as a predictor of weight change and behavior change in the premier trial. J. Nutr. Educ. Behav. 2013; 45, 314-21.

[31] H Leventhal, I Brissette and EA Leventhal. The Common-Sense Model of Self-Regulation of Health and Illness. In: L Cameron and $\mathrm{H}$ Leventhal (Eds.). The Self-Regulation of Health and Illness Behavior. Routledge, New York, 2003, p. 42-65.

[32] S Chen, J Tsai and W Lee. The impact of illness perception on adherence to therapeutic regimens of patients with hypertension in Taiwan. J. Clin. Nurs. 2009; 18, 2234-44.

[33] BH Munro. Statistical Methods for Health Care Research. $4^{\text {th }}$ ed. Lippincott, Philadelphia, 2001.

[34] Self-efficacy for Managing Chronic Disease 6-item Scale. Available at: http://patienteducation. stanford.edu/research/secd6.html, accessed July 2013.

[35] S Leelacharas. 2005, Illness Representations in Thai Women Diagnosed with Hypertension and Relationships to Medication-Taking Behavior. Ph. D. Dissertation, University of Michigan, USA.

[36] S Limcharoen. 2006, Factor Related to Adherence to Treatment among Essential Hypertensive Patients. Master's Thesis, Burapha University, Chonburi, Thailand.

[37] GM Maruyama. Basic Structural Equation Modeling. Sage, Thousand Oaks, California, 1998.

[38] JB Schreiber, A Nora, FK Stage, EA Barlow and J King. Reporting structural equation modeling and confirmatory factor analysis results: A review. J. Educ. Res. 2006; 99, 323-38.

[39] BG Tabachnick and LS Fidell. Using Multivariate Statistics. Vol. II, $5^{\text {th }}$ ed. Pearson Education, Boston, Miami, 2007.

[40] I Ajzen. Perceived behavioral control, self-efficacy, locus of control, and the Theory of Planned Behavior. J. Appl. Soc. Psychol. 2002; 32, 665-83.

[41] RM Peters and TN Templin. Theory of Planned Behavior, self-care motivation, and blood pressure self-care. Res. Theor. Nurs. Pract. 2010; 24, 172-86.

[42] N Baiya. 2011, Patient Factors and Family Factors Influencing Health Behavior of Hypertensive Patients. Master's Thesis, Burapha Univerity, Chonburi, Thailand.

[43] JS House, KR Landis and D Umberson. Social relationships and health. Science 1988; 241, 540-45.

[44] K Glanz, BK Rimer and K Viswanath. Health Behavior: Theory, Research, and Practice. $5^{\text {th }}$ ed. A Wiley Brand, Jossey-Bass, California, 2015.

[45] American Heart Association. Available at: http://www.heart.org/HEARTORG/Conditions/ HighBloodPressure/SymptomsDiagnosisMonitoringofHighBloodPressure/What-are-the-Symptomsof-High-Blood Pressure_UCM_301871_Article.jsp\#.WBonAMk-u99, accessed December 2016.

[46] S Leelacharas and D Rujiwatthanakorn. Thai women's perceptions of the causes of hypertension based on age and educational level. Pac. Rim Int. J. Nurs. Res. Thai. 2012; 16, 3-12. 